\title{
Trophic State EVAluation OF SELECTED LAKES in GRAND Teton NATIONAL PARK
}

\author{
WOODRUFF MILLER $\uparrow$ CIVIL ENGINEERING DEPARTMENT \\ BRIGHAM YOUNG UNIVERSITY $\uparrow$ PROVO $\downarrow$ UT
}

\section{$\uparrow \quad$ INTRODUCTION}

This short report is the summary of the 120 page complete report describing the trophic status evaluation of seventeen lakes located in Grand Teton National Park, Wyoming. The study was motivated by concern that the water quality of the lakes within the Park may be declining due to increased human usage over the past several years. The trophic status evaluation, featuring nutrient and chlorophyll-a analyses, was chosen because it is believed to be a sound indicator of the lakes' overall water quality.

The literature review proved unsuccessful in finding any trophic status studies which had been previously conducted on the Teton lakes. As a result, it was not possible to identify any changes in water quality over time. Therefore, this report may serve as a guideline with which future studies may be compared.

The seventeen lakes selected for the study were grouped according to their elevation and location within the Park. The groups and their respective lakes are as follows: Mountain Lakes; Amphitheater, Lake of the-Crags, Delta, Holly, Solitude, and Surprise, Moraine Lakes; Bradley, Jenny, Leigh, Phelps, String, and Taggart, Valley Lakes; Christian Pond, Emma Matilda, and Two Ocean, and Colter Bay Lakes; Cygnet Pond and Swan Lake.

\section{EUTROPHICATION}

Natural lake systems become more and more productive over time. Eventually, all lakes begin filling up, become swamps, and ultimately dry land. This gradual process is called eutrophication. Nutrients, in particular phosphorus and nitrogen, contribute to an increased growth of the biota of the lake. This natural eutrophication is a slow process, frequently taking place over periods of thousands of years. However, human interaction tends to speed up the eutrophication process. This is referred to as cultural eutrophication which is nearly always a result of introducing above-normal quantities of nitrogen and phosphorus into aquatic systems.

Primary production in lake systems is normally limited by nitrogen, phosphorus, carbon, temperature, turbidity, shading or toxins. However, nitrogen and phosphorus are the most common limiting factors. Ratios of total nitrogen to total phosphorus of greater than 20:1 give a strong indication of phosphorus limitation. Ratios less than 10:1 give a strong indication of nitrogen shortage relative to phosphorus.

Phosphorus is limiting in a much higher percentage of lakes than nitrogen. This initial study focused on using phosphorus as an indicator of productivity. The water samples were not analyzed for nitrogen, so it was not possible to calculate N/P 
ratios. Although this makes it difficult to be certain which nutrient is limiting, the data which were collected did indicate possible nutrient limiting circumstances, as discussed in the Conclusions section of this report.

\section{TROPHIC STATE DESCRIPTIONS}

The lake trophic state refers to the biological productivity of the lake and is a strong indicator of the lake's overall water quality. The purpose of this study was to classify each of the lakes into one of the following four categories.

Oligotrophic: An oligotrophic lake has an overall high water quality. Characteristics of these lakes are: low nutrients and productivity, transparent water, a more sandy/rocky shoreline and bottom, less debris, slightly cooler water, fewer insects and fish, etc. Examples of such lakes are Lake Tahoe and Yellowstone Lake.

Eutrophic: The term "eutrophic" has been used for many years to describe a polluted or undesirable condition in a lake. In actuality, eutrophic lakes are biologically healthy, typically supporting a large number and wide variety of species. Eutrophic lake characteristics include: high nutrient levels, excessive plant growth, algal blooms, large quantities of debris, warmer surface temperatures, wider fluctuations in water quality, more insects and fish, undesirable "trash" fish species, etc. An example of a eutrophic lake is Utah Lake.

Mesotrophic: A mesotrophic lake is somewhere in between oligotrophic and eutrophic. Mesotrophic lakes have moderate productivity and good water quality. An example of such a lake is Bear Lake.

Hyper-eutrophic: A hyper-eutrophic lake is a eutrophic lake which is even further degraded and has more excessive productivity and even poorer water quality.

We assumed that the majority of the lakes would fall within the oligotrophic to slightly mesotrophic ranges because the lakes are located in pristine natural surroundings and are made up of water originating from high mountain snowpack and runoff. If any lakes were found to be in the eutrophic range, this would suggest that human involvement in the Park may have altered water quality for the worse.

\section{TROPHIC STATE MODELS}

The models used to determine the trophic status of the Teton lakes are described below.

Carlson Trophic State Index Model: The Carlson Trophic State Index (TSI) uses three in-lake indicators to classify the trophic status of a lake. Secchi depth measurements indicate lake transparency, chlorophyll-a concentrations indicate the amount of algal biomass, and total phosphorus concentrations indicate the nutrient availability to drive algae growth. These three indicators yield a TSI value which is used to designate the trophic status of the lake.

Vollenweider Model: This model classifies the trophic status of the lake by plotting the inflow total phosphorus (T-P) concentration in ppb versus the lake hydraulic residence time in years. The hydraulic residence time is the lake volume divided by the average annual outflow of the lake, and is an indication of how long the water may reside in the lake. An estimation of the annual outflow rate was made based on our measured summer inflows and considering that there is little if any inflow in the fall and winter.

Larsen Mercier Model: The Larsen Mercier Model is similar to Vollenweider's Model. The inflow total phosphorus (T-P) concentration in $\mathrm{mg} / \mathrm{l}$ is plotted versus the phosphorus retention coefficient which is calculated by subtracting the outflow T-P load from the inflow T-P load and dividing this difference by the inflow T-P load. In most cases in this study, the in-lake T-P concentrations were used in place of the outflow T$P$ concentrations. While this approach is not exactly correct, it did give a reasonable approximation of the phosphorus retention coefficient and allowed qualified application of the model for lakes with residence times of less than six months. For lakes with residence times greater than six months, less weight was given to the Larsen Mercier Model in designating lake trophic status.

Phosphorus retention can be thought of as the ability of the lake to utilize phosphorus for plant and algae production. If primary production is high, the in-lake and outflow T-P will be low, and the phosphorus retention coefficient will be high. In 
many of the Teton lakes, the outflow (in-lake) phosphorus is equal to or greater than the phosphorus measured in the inflow stream, which yields a zero or negative retention coefficient.

\section{DATA COLLECTION AND ANALYSIS}

Our sampling trips were scheduled for the summer season when the lakes are accessible and free of ice. We felt that the ideal time to collect samples was in the early summer after the mountain lakes thawed and again in the late summer. An unusually cold and wet spring with a heavy mountain snowpack made sample collection of the Mountain Lakes in June impossible. However, June sample collection of the lower lakes was conducted. A July trip was made in order to take the first samples of the Mountain Lakes. The second set of samples were taken in August as planned. Another sampling trip was also made in early October.

Each lake was sampled a minimum of two times in at least one location. Some of the lakes were sampled more frequently and in more than one location. Each lake main inlet (inlets) was also sampled two times. Most lake samples were collected via a small, one-man, inflatable rubber raft which was backpacked into the lake. A few of the lakes which were accessible by road were sampled using a canoe. The raft or canoe enabled samples to be taken from the middle of the lake rather than from the bank. The raft or canoe also provided a means for using the Secchi disk to measure the lake transparency and to determine the depth of the lake.

Lake and inlet samples were used for analysis of chlorophyll-a and specific conductivity. Samples were also taken from the lakes and inlets for nutrient analysis in $500 \mathrm{ml}$ bottles prepared with a sulfuric acid solution. This allowed in-lake and inflow phosphorus concentrations to be determined for the Carlson Model and for the Vollenweider and Larsen Mercier Models respectively. Since the study was related to trophic analysis, many water quality parameters weren't measured. However, specific conductivity, a parameter which can be used to compare quality among all water samples at any temperature, was measured and the results are given in the report. The lake temperature and $\mathrm{pH}$ were also measured.

The chlorophyll-a analysis was conducted at the Pacific Northwest Regional Laboratories of the Bureau of Reclamation in Boise, Idaho. We express special appreciation to this lab for their gratuitous work and significant contribution to this project. The total phosphorus concentrations and conductivities were obtained from Brigham Young University Laboratories.

\section{$\uparrow \quad$ RESULTS}

Each lake was evaluated and classified according to the trophic status diagram below.

For the purposes of this study, slightly oligotrophic or slightly eutrophic refers to a status which is close to the mesotrophic zone, while strongly oligotrophic or strongly eutrophic refers to a status which is furthest from the mesotrophic zone. In addition, we have arbitrarily defined slightly mesotrophic as a status close to the oligotrophic zone and strongly mesotrophic as a status close to the eutrophic zone.

In the complete 120 page reports, which are available in Laramie, Moose, and Provo, the water quality and trophic evaluation results are presented in sections for each lake of between 4 to 7 pages. These include a description of the lake location and physical characteristics, the sampling dates and flow measurements, and a photograph of the lake. A table with selected field and lab water quality data is also included along with an analysis of the values.

\begin{tabular}{|c|c|c|c|c|c|c|c|c|}
\hline \multicolumn{9}{|c|}{ TROPHIC STATUS } \\
\hline \multicolumn{3}{|c|}{ OLIGOTROPHIC } & \multicolumn{3}{c|}{ MESOTROPHIC } & \multicolumn{3}{c|}{ EUTROPHIC } \\
\hline $\begin{array}{c}\text { Strongly } \\
\text { Oligotrophic }\end{array}$ & Oligotrophic & $\begin{array}{c}\text { Slightly } \\
\text { Oligotrophic }\end{array}$ & $\begin{array}{c}\text { Slightly } \\
\text { Mesotrophic }\end{array}$ & Mesotrophic & $\begin{array}{c}\text { Strongly } \\
\text { Mesotrophic }\end{array}$ & $\begin{array}{c}\text { Slightly } \\
\text { Eutrophic }\end{array}$ & Eutrophic & $\begin{array}{c}\text { Etrongly } \\
\text { Eutrophic }\end{array}$ \\
\hline
\end{tabular}


The Carlson Model results for each sampling date and location are shown on the Carlson TSI Figures and a Carlson trophic status is designated. Likewise, the sections for each lake also include the phosphorus data shown on the Vollenweider and Larsen Mercier Diagrams and the trophic status based on each of these models is designated. The overall lake trophic classification is then determined from the average or weighted average of the results of these three models.

A definitive conclusion as to the trophic status of some lakes was not able to be made and further sampling and analysis are needed. The complete report also includes comprehensive tables which summarize all the physical data and water quality data which were collected for the trophic state evaluations. Table 1 shows our results for the trophic classifications of all of the Teton lakes which were evaluated.
The Colter Bay Lakes, Cygnet Pond and Swan Lake, were sampled more frequently and more extensively than the other lakes in the study. Sewage disposal ponds are located between Swan Lake and Cygnet Pond. Cygnet Pond was used as the control lake because it is located up gradient from these sewage lagoons and Swan Lake is located down gradient.

In addition to the six rounds of normal trophic status testing, Swan Lake and Cygnet Pond were also sampled for total coliforms and fecal coliforms. As shown in Table 2, this first series of tests showed mixed indications of any significant differences in coliform concentrations among Swan Lake, it's inlet, and Cygnet Pond. Since the coliform tests were inconclusive, future evaluations might include testing for Escherichia coli and also analyzing fecal coliform to fecal streptococci ratios in order to detect the presence of human feces from the lagoons.

\begin{tabular}{|c|c|c|c|}
\hline Lake & Classification & Lake & Classification \\
\hline \multicolumn{4}{|c|}{ Mountain Lakes } \\
\hline Amphitheater Lake & slightly oligotrophic & Lake of the Crags & slightly oligotrophic ${ }^{*}$ \\
\hline Delta Lake & slightly oligotrophic & Holly Lake & slightly mesotrophic \\
\hline Lake Solitude & strongly oligotrophic & Surprise Lake & slightly mesotrophic \\
\hline \multicolumn{4}{|c|}{ Moraine Lakes } \\
\hline Bradley Lake & slightly mesotrophic & Jenny Lake & slightly oligotrophic \\
\hline Leigh Lake & strongly oligotrophic & Phelps Lake & no definite conclusion ${ }^{*}$ \\
\hline String Lake & oligotrophic & Taggart Lake & slightly mesotrophic \\
\hline \multicolumn{4}{|c|}{ Valley Lakes } \\
\hline Christian Pond & mesotrophic ${ }^{*}$ & Emma Matilda Lake & slightly mesotrophic \\
\hline Two Ocean Lake & no definite conclusion ${ }^{*}$ & & \\
\hline \multicolumn{4}{|c|}{ Colter Bay Lakes } \\
\hline Cygnet Pond & mesotrophic ${ }^{*}$ & Swan Lake & slightly mesotrophic ${ }^{*}$ \\
\hline
\end{tabular}




\begin{tabular}{|c|c|c|c|c|c|c|}
\hline \multirow{2}{*}{ Location } & \multicolumn{3}{|c|}{ Fecal Coliforms (CFU's/100ml) } & \multicolumn{3}{|c|}{ Total Coliform (CFU's $/ 100 \mathrm{ml})$} \\
\hline & 24 July & 4 Sept & 1 Oct & 24 July & 4 Sept & 1 Oct \\
\hline Swan Lake & 220 & 20 & $<100$ & TNTC & 200 & 2,400 \\
\hline Swan Inlet & - & 380 & $<100$ & $\overline{-}$ & 3,000 & 700 \\
\hline Cygnet Pond & - & - & 100 & - & - & 1,700 \\
\hline
\end{tabular}

Readers are encouraged to consult the complete report if the details resulting in these trophic status determinations are of interest. Copies of the report are available from Dr. Wood Miller at BYU Civil and Environmental Engineering, Provo, UT 84602.

\section{CONCLUSIONS}

The overall water quality in the Park with respect to trophic status is quite high. Most of the lakes were found to be in the slightly oligotrophic to slightly mesotrophic ranges. None of the lakes were found to be in the eutrophic range.

\section{TROPHIC STATE EVALUATIONS}

Mountain Lakes: All of the Mountain Lakes, with the exception of Lake Solitude, were found to be slightly oligotrophic to slightly mesotrophic. Lake Solitude was found to possess the highest water quality in the study and was classified as strongly oligotrophic. This lake is located the furthest west of any of the lakes in the study and received the lowest inflow phosphorus concentrations. Further study of this interesting observation may be warranted.

Moraine Lakes: The Moraine Lakes were also in the oligotrophic to slightly mesotrophic ranges, with the exception of Leigh Lake, which was found to be strongly oligotrophic. We were unable to classify Phelps Lake due to inconsistencies in the data. Phelps Lake recorded unusually high inflow phosphorus concentrations and low in-lake phosphorus concentrations. Normally this would indicate that most of the inflow phosphorus was being used for primary production and that the lake was phosphorus limited. However, the in-lake algae production, measured as chlorophyll-a in the Carlson Model, is lower than would be expected under these circumstances. It is possible that the August inflow phosphorus concentration of $244 \mathrm{ppb}$ may be an anomaly. In order to better understand the trophic state of Phelps Lake, more sampling is recommended.

Valley Lakes: The Valley Lakes were somewhat lower in water quality than the Mountain and Moraine Lakes. Emma Matilda Lake was classified as slightly mesotrophic and Christian Pond was classified as mesotrophic. Only Cygnet Pond was found to have a more productive trophic state than Christian Pond. Both of these lakes are designated as swan breeding grounds. Therefore, some difficulty arose in sampling the ponds without disturbing the swans. Samples were collected from near the bank or the outlet rather than from the middle of the ponds which may have altered the results. Further analysis of both of these ponds is recommended.

The models were too inconsistent to classify Two Ocean Lake. The Carlson Model suggested strongly mesotrophic conditions and the Vollenweider Model indicated both oligotrophic and eutrophic conditions. Since the Larsen Mercier Model is less credible, due to the long hydraulic residence time, it is not possible to make a sound classification. Further testing is recommended for Two Ocean Lake. This should also include sampling the west inlet of the lake, which was not sampled.

Colter Bay Lakes: Both of the Colter Bay Lakes were classified in the mesotrophic range. Cygnet Pond was found to be mesotrophic and 
Swan Lake was slightly mesotrophic. As was previously discussed, further testing on these lakes should focus on methods to detect the presence of human feces. A water sample was taken in a marshy area down gradient from the sewage lagoon ponds. This sample was found to be very high in total phosphorus (269 ppb) indicating the slight possibility that sewage may be leaking from the ponds since wastewater is commonly high in phosphorus.

\section{NUTRIENT LIMITATIONS}

Many of the lakes in the study may be nitrogen limited. Two scenarios indicate possible nitrogen limiting circumstances in the lakes.

The first circumstance, illustrated by the Carlson Model, is when in-lake T-P is high and inlake chlorophyll-a concentration is low. This is an indication that nitrogen is limiting the growth of algae since phosphorus is readily available and not being used. This phenomenon was observed in Amphitheater Lake, Lake of the Crags, Delta Lake, Holly Lake, Surprise Lake, Jenny Lake, Christian Pond, Emma Matilda Lake, Two Ocean Lake, Cygnet Pond, and Swan Lake.

The other circumstance is when a zero phosphorus retention coefficient is calculated for the Larsen Mercier Model. A zero coefficient occurs when the in-lake $T-P$ is equal to the inflow $T-P$. This condition indicates that the phosphorus which is entering the lake is not being utilized in primary production and algal growth is being limited by some other factor. Lakes which had zero phosphorus retention coefficients include: Amphitheater Lake, Delta Lake, Holly Lake, Lake Solitude, Surprise Lake, Bradley Lake, Leigh Lake, String Lake, Christian Pond, Emma Matilda Lake, Two Ocean Lake, Cygnet Pond, and Swan Lake.

Several factors can limit primary production in lake systems such as nitrogen, phosphorus, carbon, temperature, turbidity, shading and toxins. However phosphorus and nitrogen are the most common limiting factors and phosphorus is limiting in a much higher percentage of lakes than nitrogen.

The above mentioned lakes appear to be limited by a factor other than phosphorus. If not nitrogen, it is quite possible that they are temperature limited. This is especially true in the
Mountain Lakes where the average summer in-lake temperature was $8^{\circ} \mathrm{C}\left(46^{\circ} \mathrm{F}\right)$. The two lakes not listed above, Phelps Lake and Taggart Lake, are assumed to be phosphorus limited.

\section{$\downarrow \quad$ BIBLIOGRAPHY}

Canfield, Daniel E. and Roger W. Bachman. "Prediction of Total Phosphorus Concentrations, Chlorophyll-a, and Secchi Depths in Natural and Artificial Lakes." Canadian Journal of Fisheries and Aquatic Sciences. Vol. 38, No. 4. pp 414-423. 1981.

Carlson, Robert E. "A Trophic State Index for Lakes." Limnology and Oceanography. Vol. 22, No. 2. pp. 361-369. 1977.

Porcella, Donald B. et al. "Index to Evaluate Lake Restoration." Journal of the Environmental Engineering Division. Vol. 106, No.6. Dec. 1980.

Sawer, Clair N. And Perry L. McCarty. Chemistry for Environmental Engineering. McGrawHill, Inc. New York: 1978.

Tchobanoglous, George and Edward D. Schroeder. Water Quality. Addison-Wesley Publishing Co. USA: 1985.

The Lake and Reservoir Restoration Guidance Manual 2nd Edition. Prepared by the North American Lake Management Society for the United States EPA. 1990.

Vollenweider, R. A. Sc. "Fundamentals of the eutrophication of lakes and flowing water..." Technical Report OECH, Paris, France, DAS/CSI/68.27 1968.

Wetzel, Robert G. Limnology 2nd Edition. Saunders College Publishing. 1983. 